\title{
Review \\ Overview of the Ultrasound Classification Systems in the Field of Thyroid Cytology
}

\author{
Esther Diana Rossi ${ }^{1, *} \mathbb{0}$, Liron Pantanowitz ${ }^{2}$, Marco Raffaelli ${ }^{3}$ and Guido Fadda ${ }^{1,4}$ \\ 1 Division of Anatomic Pathology and Histology, Fondazione Policlinico Universitario Agpstino Gemelli, \\ 00168 Rome, Italy; guido.fadda@unime.it \\ 2 Department of Pathology \& Clinical Labs, University of Michigan, Ann Arbor, MI 48103, USA; \\ lironp@med.umich.edu \\ 3 Division of Endocrine-Surgery, Fondazione Policlinico Universitario Agpstino Gemelli, 00168 Rome, Italy; \\ marco.raffaelli@policlinicogemelli.it \\ 4 D.A.I. Diagnostic Department of Anatomic Pathology, University of Messina, 98100 Messina, Italy \\ * Correspondence: esther.rossi@policlinicogemelli.it
}

check for updates

Citation: Rossi, E.D.; Pantanowitz,

L.; Raffaelli, M.; Fadda, G. Overview of the Ultrasound Classification Systems in the Field of Thyroid Cytology. Cancers 2021, 13, 3133. https://doi.org/10.3390/cancers 13133133

Academic Editor: Chan-Kwon Jung

Received: 17 May 2021

Accepted: 21 June 2021

Published: 23 June 2021

Publisher's Note: MDPI stays neutral with regard to jurisdictional claims in published maps and institutional affiliations.

Copyright: (c) 2021 by the authors. Licensee MDPI, Basel, Switzerland. This article is an open access article distributed under the terms and conditions of the Creative Commons Attribution (CC BY) license (https:// creativecommons.org/licenses/by/ $4.0 /)$.
Simple Summary: Ultrasound (US) is the preferred imaging modality for thyroid nodule evaluation. Accurate US assessment of thyroid lesions can help decrease unwarranted FNA procedures of benign nodules. Several thyroid nodule risk classification systems that focus on US features have been published. Some of them highlight simple US patterns, while others rely on the presence of multiple US features to categorize thyroid nodules. The current review offers an evaluation of different US system, combining them with the use of fine needle aspiration and the cytological classification systems.

Abstract: The increasing application of ultrasound (US) in recent years has led to a greater number of thyroid nodule diagnoses. Consequently, the number of fine needle aspirations performed to evaluate these lesions has increased. Although the majority of thyroid nodules are benign, identifying methods to define specific lesions and tailor risk of malignancy has become vital. Some of the tools employed to stratify thyroid nodule risk include clinical factors, thyroid US findings, and reporting systems for thyroid cytopathology. Establishing high concordance between US features and cytologic diagnoses might help reduce healthcare costs by diminishing unnecessary thyroid procedures and treatment. This review aims to review radiology US classification systems that influence the practice of thyroid cytology.

Keywords: thyroid; classification system; follicular neoplasm; ultrasound classification system; TIRAD

\section{Introduction}

Thyroid nodules are common in adults. In recent years, the incidence rate of thyroid cancer has increased, as has the rate of thyroidectomy [1,2]. However, the overall mortality for thyroid malignancy during this time period showed no significant changes. The increase in diagnosing thyroid lesions is partly attributed to improvements in imaging technology and increased use of imaging, which leads to higher rates of thyroid nodule detection [3-5]. As a result, finer needle aspiration (FNA) biopsies and, accordingly, a higher incidence of subclinical thyroid cancer has risen. FNA is the first and perhaps most important minimally invasive diagnostic tool employed in the evaluation of thyroid nodules [6-11]. Around $70 \%$ of thyroid nodules are benign, with only $5-10 \%$ reported to be malignant $[1,2]$. The remaining 20-25\% of thyroid lesions comprise grey zone indeterminate proliferations that include either benign or malignant lesions, for which morphological discrimination alone is not always possible. These aspects raised concerns over the costs and morbidity linked with the management of patients with thyroid nodules. On the whole, it often leads to unnecessary surgical resections and drives up healthcare cost. It stands to reason that a 
more refined and accurate approach to the management of thyroid lesions needs to start from an accurate initial workup including US evaluation, avoiding the over-diagnosis of low-risk lesions [2-6].

According to the American Thyroid Association (ATA), ultrasound (US) is the main and preferred imaging modality for thyroid nodule evaluation [7]. Accurate US assessment of thyroid lesions can help decrease unwarranted FNA procedures of benign nodules. Several thyroid nodule risk classification systems that focus on US features have already been published. Some of them highlight only simple US patterns, while others rely on the presence of multiple US features to categorize thyroid nodules. In 2009, Horvath et al. proposed a Thyroid Imaging, Reporting and Data System (TIRADS) [12] (Table 1) accepted and then proposed by the American College of Radiology (ACR) and based upon the distribution of US features in five categories (composition, echogenicity, shape, margin, and echogenic foci) [13,14]. The TIRADS reporting system has notably been modeled after the 2009 Breast Imaging Reporting and Data System (BIRADS) [15].

Table 1. Summary of the main features of ultrasound-based thyroid nodule systems.

\begin{tabular}{|c|c|c|}
\hline ACR-TIRADS & Korean System & UK BTA System \\
\hline $\begin{array}{l}\text { TR } 1 \\
0 \text { points } \\
\text { Benign }\end{array}$ & K-TIRADS 1: no nodule & U1: No nodule \\
\hline $\begin{array}{c}\text { TR } 2 \\
2 \text { points } \\
\text { no suspicious }\end{array}$ & K-TIRADS 2: Benign & $\begin{array}{l}\text { U2: Benign } \\
\text { hyperechoic or isoechoic with a halo } \\
\text { cystic change with ring-down artifact (colloid) } \\
\text { - microcystic or spongiform appearance } \\
\text { - } \quad \text { peripheral egg-shell calcification } \\
\text { - } \quad \text { peripheral vascularity }\end{array}$ \\
\hline $\begin{array}{l}\text { TR } 3 \\
3 \text { points } \\
\text { Mildly suspicious }\end{array}$ & $\begin{array}{l}\text { K-TIRADS 3: Low } \\
\text { partially cystic/isohyperechoic with } \\
\text { no suspicious features }\end{array}$ & $\begin{array}{l}\text { U3: Indeterminate } \\
\text { solid homogenous markedly hyperechoic nodule with halo } \\
\text { (follicular lesions) } \\
\text { - hypoechoic with equivocal echogenic foci or cystic } \\
\text { change } \\
\text { - mixed or central vascularity }\end{array}$ \\
\hline $\begin{array}{c}\text { TR } 4 \\
\text { TR } 4 \mathrm{a}=4 \\
\text { TR } 4 \mathrm{~b}=5 \\
\text { TR } 4 \mathrm{c}=6 \\
\text { from } 4 \text { to } 6 \text { points } \\
\text { Moderately suspicious }\end{array}$ & $\begin{array}{l}\text { K-TIRADS 4: Intermediate } \\
\text { as for K-TIRADS } 3 \text { but with any } \\
\text { suspicious features or as for } \\
\text { K-TIRADS } 5 \text { without suspicious } \\
\text { features }\end{array}$ & $\begin{array}{l}\text { U4: Suspicious } \\
\text { solid hypoechoic (compared with thyroid) } \\
\text { - } \quad \text { solid very hypoechoic (compared with strap muscles) } \\
\text { - } \quad \text { hypoechoic with disrupted peripheral calcification } \\
\text { lobulated outline }\end{array}$ \\
\hline & & $\begin{array}{l}\text { U5 Malignant } \\
\text { solid hypoechoic with a lobulated or irregular outline and } \\
\text { microcalcification }\end{array}$ \\
\hline $\begin{array}{l}\text { TR } 5>7 \text { points } \\
\text { Highly suspicious }\end{array}$ & $\begin{array}{l}\text { K-TIRADS 5: High } \\
\text { solid hypoechoic nodule with any } \\
\text { suspicious feature }\end{array}$ & $\begin{array}{ll}\text { - } & \text { papillary carcinoma } \\
\text { - } & \text { solid hypoechoic with a lobulated or irregular outline } \\
\text { - } & \text { med globular calcification } \\
\text { - } & \text { intranodular vascularity } \\
\text { - } & \text { taller than wide axially }(\mathrm{AP}>\mathrm{ML}) \\
\text { - } & \text { characteristic associated lymphadenopathy }\end{array}$ \\
\hline
\end{tabular}


In 2015, Grant et al. published a thyroid ultrasound reporting lexicon in which all thyroid nodules were classified on the basis of TIRADS categories which, in turn, not only defined their risk of malignancy but offered evidence-based recommendations to manage thyroid nodules based on their size and sonographic features [5]. After the first Korean version of the TIRADS system by Kwak et al. [14], Shin et al. (2016) subsequently proposed a revised Korean Society of Thyroid Radiology (KSThR) consensus statement with recommendations in which specific sonographic features were used to stratify the risk of thyroid nodules into four categories [8]. According to the published literature, the Korean-TIRADS has been successfully used for US evaluation of thyroid nodules in order to stratify the need for these nodules to undergo FNA (Table 1).

The 2015 ATA guideline includes a detailed description of sonographic features, categorizing thyroid nodules that utilize one of the described patterns [7]. The most suspicious US features include margins, microcalcifications, "taller-than-wide" shape", rim calcifications, and evidence of extrathyroidal extension. Specifically, the ATA defined and identified five categories: (1) Benign ( $\mathrm{ROM}<1 \%$ ); (2) very low suspicion ( $\mathrm{ROM}<3 \%$ in lesions $\geq 20 \mathrm{~mm}$ ); (3) low suspicion (ROM 5-10\% in lesions $\geq 15 \mathrm{~mm}$ ); (4) Intermediate suspicion (ROM 10-20\% in lesions $\geq 10 \mathrm{~mm}$ ); and (5) high suspicion (ROM 70-90\% in lesions $\geq 10 \mathrm{~mm}$ ).

Furthermore, the European Thyroid Association (ETA) TIRADS, which includes five categories, was published in 2017 by Russ et al., with the main purpose of identifying thyroid malignancies while maintaining both high negative predictive value and sensitivity [16]. Since then, several similar systems have been promoted including the recommendations from the American Association of Clinical Endocrinology (AACE), American College of Endocrinology (ACE), Associazione Medici Endocrinologi (AME), as well as comprehensive cancer network guidelines [17-19].

The current article reviews these different US classification systems and the influence they have on the practice of thyroid cytology.

\section{Overview of ACR-TIRADS}

In an attempt to stratify the risk of thyroid cancer utilizing US features, the TIRADS imaging risk stratification system was proposed by Horvath et al. from Chile in 2009 and further modified by Kwak et al. from Seoul in 2011 [12,14]. TIRADS is now accepted by the ACR and has been described in a paper published by the ACR TIRADS Committee [5].

The ACR-TIRADS is designed to reduce the number of unnecessary FNA procedures performed for benign thyroid nodules with an objective to increase the diagnostic efficacy of evaluating thyroid nodules. The idea behind this system is to codify all thyroid lesions into diagnostic US categories. Specifically, five different US characteristics of a thyroid nodule are evaluated, including: (a) composition, (b) echogenicity, (c) shape, (d) margin, and (e) echogenic foci (Table 2). Points are assigned to each of these US features. For composition, the values are as follows: cystic or spongiform $=0$, mixed solid-cystic $=1$, and solid $=2$. For echogenicity, they are anechoic $=0$, isoechoic or hyperechoic $=1$, hypoechoic $=2$, and very hypoechoic $=3$. For shape, wider-than-tall $=0$, whilst taller-than-wide $=3$. Margins are classified as follows: smooth or ill-defined $=0$, irregular or lobulated $=2$, and extrathyroidal extension $=3$. The echogenic foci are classified as: none or comet-tail $=0$, macrocalcifications $=1$, peripheral or rim calcifications $=2$, and punctate $=3$. Points are totaled by adding single selections from the five nodular characteristics and they are then used to classify thyroid nodules into TIRADS categories as follow: TR1 = Benign (requires no FNA), TR2 = not suspicious for malignancy (requires no FNA-Figure 1), TR3 = mildly suspicious (FNA if $\geq 2.5 \mathrm{~cm}$ and follow if $\geq 1.5 \mathrm{~cm}$ ), TR4 $=$ moderately suspicious (FNA if $\geq 1.5 \mathrm{~cm}$ and follow if $\geq 1.0 \mathrm{~cm}$-Figure 2 ), and TR $5=$ highly suspicious (FNA if $\geq 1.0 \mathrm{~cm}$ and follow if $\geq 0.5 \mathrm{~cm}$-Figure 3). Concerning TR4, there was a further subclassification including TR4a with one malignant sign and possibly benign; TR4b with two malignant signs and possible malignant; TR4c with three or four malignant signs and highly possible malignant. Furthermore, the TIRAD Committee underlined the risk of malignancy (ROM) 
for each category as follows: $2 \%$ or less for TR 1 and TR2, $2.1-5 \%$ for TR3, $5.1-20 \%$ for TR4, and greater than $20 \%$ for TR5. As indicated, the categories along with thyroid nodule size help determine recommendations for FNA and follow-up management.

Table 2. Criteria adopted for the definition of the TIRADS system score categories.

\begin{tabular}{cc}
\hline Criteria & Definitions \\
\hline Compositic $=0$ \\
Spongiform $=0$ \\
Mixed solid and cystic $=1$ \\
Solid $=2$ \\
\hline Echogenecity & Anechoic $=0$ \\
& Hyperechoic or isoechoic $=1$ \\
Hypoechoic $=2$ & Very hypoechoic $=3$ \\
\hline \multirow{2}{*}{ Shape } & Wider-than-tall $=0$ \\
& Taller-than-wide $=3$ \\
\hline \multirow{2}{*}{ Margins } & Smooth $=0$ \\
& Ill-defined $=0$ \\
& Lobulated or irregular $=2$ \\
& Extrathyroid extension $=3$ \\
\hline \multirow{2}{*}{ Echogenic foci } & None or large comet-tail artifacts $=0$ \\
& Macrocalcifications $=1$ \\
& Peripheral calcifications $=2$ \\
Punctate echogenic foci $=3$
\end{tabular}

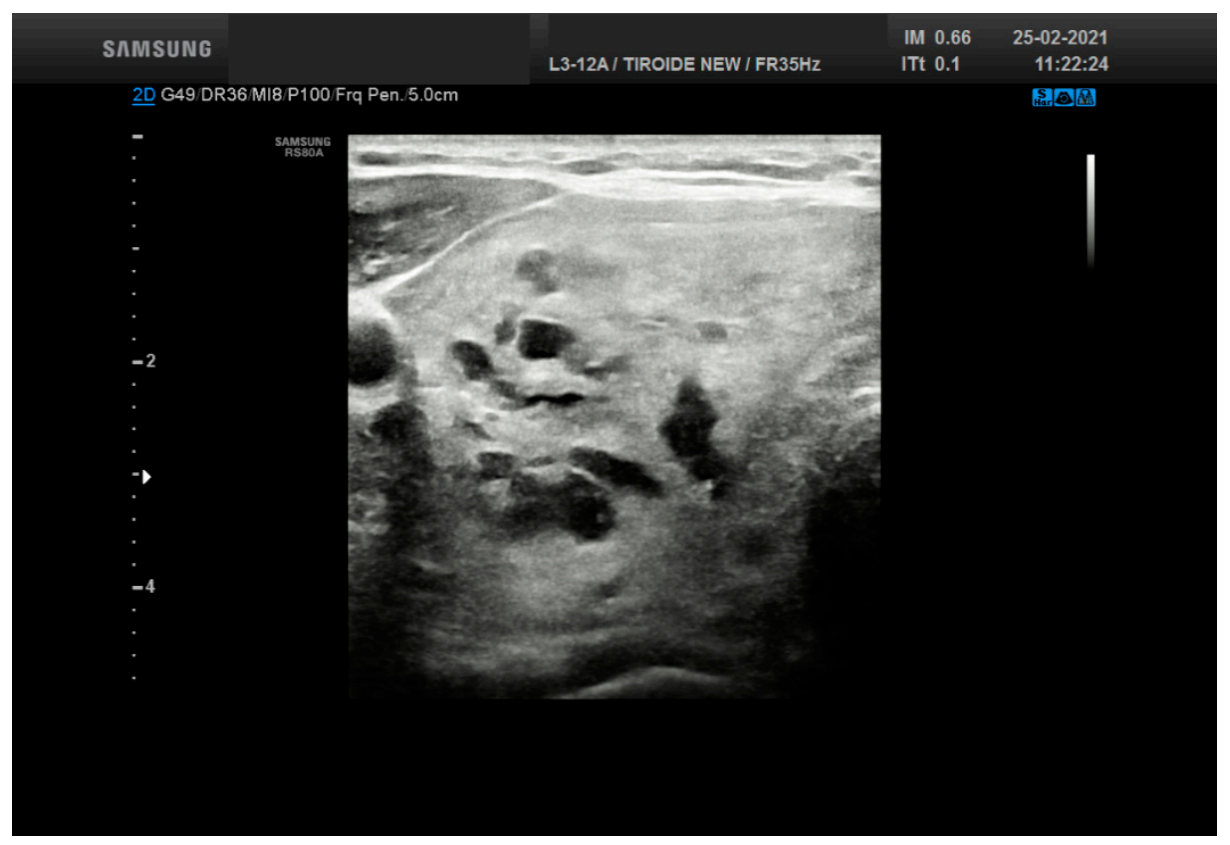

Figure 1. Ultrasound features from a thyroid nodule (50 $\mathrm{mm}$ size) resulting into a score 2 (solid and cystic plus hyperechoic-isoechoic) belonging to TR 2 . The lesion was diagnosed as adenomatous goiter. 


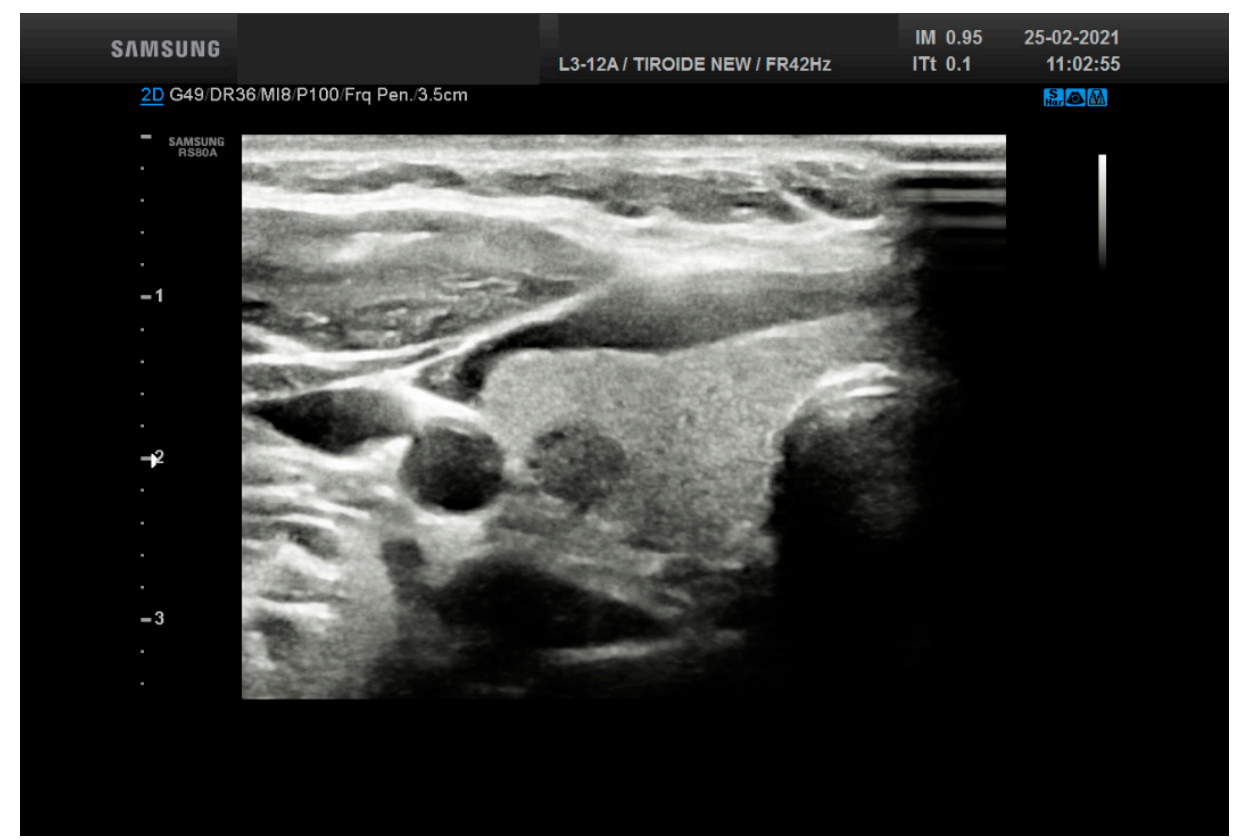

Figure 2. Ultrasound features from a thyroid nodule (15 mm size) resulting into a score 5 (solid, hypechoic with a calcification) belonging to TR 4 . The lesion was diagnosed as Follicular nodule.

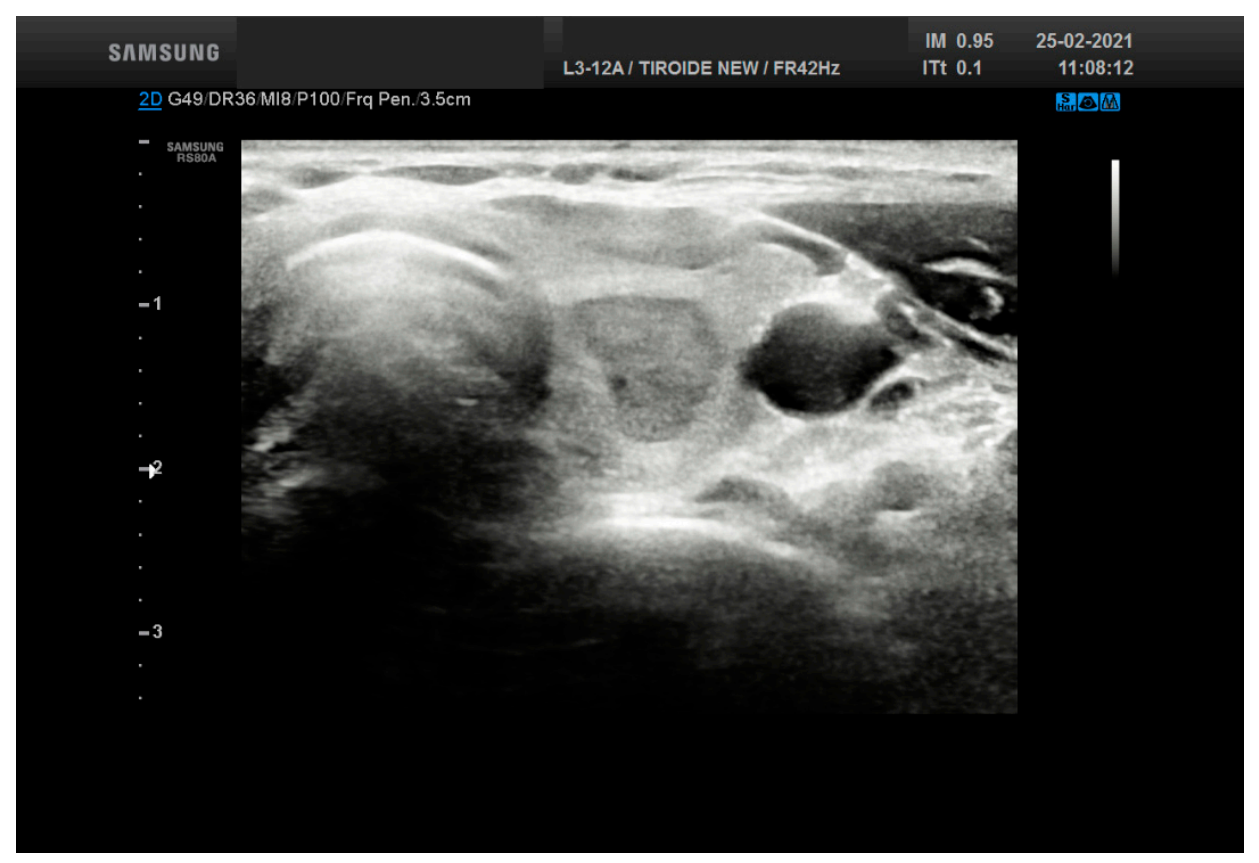

Figure 3. Ultrasound features from a thyroid nodule (15 $\mathrm{mm}$ size) resulting into a score 7 belonging to TR 5 (solid, very hypoechoic, lobulated). The lesion was diagnosed as Follicular nodule.

The novelty of ACR-TIRADS is the method of scoring both echogenic foci and calcifications, which are additive features given more weight than in other systems. Some authors have suggested modifying TIRADS [13,20-24]. Park et al. established a new system with 12 characteristics even though its application proved to be difficult, [13] and Kwak et al. proposed a more practical classification system including only five US features [14]. Several studies have evaluated the efficacy of ACR-TIRADS [20-24]. Among the others, Koseoglu et al. documented that in a series of 2847 patients who underwent FNA of their thyroid lesions ACR-TIRADS was able to classify $98.8 \%$ as benign nodules with only a minimal number of malignant lesions classified as TR2 and TR3 [20]. Ha et al. compared 
seven society guidelines, of which ACR-TIRADS resulted in the lowest rate (25.3\%) of unnecessary thyroid FNA procedures [21].

\section{TIRADS Challenges and Pitfalls}

The implementation and adoption of any new classification system are likely to present some challenges [2-6]. For ACR-TIRADS, such issues were mostly due to education, workflow, and interpretation of this reporting system. An initial step in the global adoption of a unique classification such as TIRADS is the education and training of sonographers to recognize the relevant US features. In general, a report of a thyroid nodule that received US examination should be structured and written in order to avoid colorful descriptive terms. Tappouni et al. suggested an algorithmic approach to stratify thyroid nodules, further aiding radiologists to discriminate benign from suspicious nodules [4].

As documented by Eze et al., FNA-induced reactive changes in thyroid nodules can appear worrisome and may include features such as atypical nuclei, hemorrhage, infarction, fibrinoid necrosis, fibrosis, cystic degeneration, pseudocapsular invasion, and squamous metaplasia that may resemble suspicious imaging findings, resulting in incorrectly classifying a previously aspirated thyroid nodule as TIRADS 4a [22]. Such FNA-induced changes may explain a subset of false-positive TIRADS cases, in which subsequent surgical resection of these surgeries is negative (so-called vanishing tumors).

\section{Results from Applying TIRADS}

Various studies have evaluated the prediction of thyroid malignancy using TIRADS [25-39] (Table 3). Shayganfar et al. studied 239 thyroid nodules combining TIRADS and FNA outcome using the Bethesda System for Reporting Thyroid Cytopathology (TBSRTC) [25]. The BSRTC includes six diagnostic categories including: bon-diagnostic (I); benign and bon-beoplastic (II); atypia of undetermined significance or follicular lesion of undetermined significance (AUS/FLUS) (III); follicular neoplasm or suspicious for follicular neoplasm (FN/SFN) (IV); suspicious for malignancy (SM) (V); and malignant (VI) [9]. In their study, the Bethesda system documented that thyroid nodules with TIRADS $>4$ and a diameter lower than $12 \mathrm{~mm}$ were highly suspicious for malignancy, with a sensitivity of $91.7 \%$ and specificity of $52.8 \%$. They found an inverse relationship between nodular size and malignancy risk [25].

Table 3. prediction of thyroid malignancy using TIRADS in some of the proposed studies.

\begin{tabular}{|c|c|c|c|c|c|c|c|}
\hline Series & $\begin{array}{c}\mathbf{N}^{\circ} \\
\text { Cases }\end{array}$ & Sensitivity & Specificity & PPV & NPV & $\begin{array}{l}\text { Diagnostic } \\
\text { Accuracy }\end{array}$ & $\begin{array}{c}\text { ROM (Ranged According to } \\
\text { the Cytologic Categories) }\end{array}$ \\
\hline Shayganfar [25] & 239 & $91.7 \%$ & $52.8 \%$ & / & / & / & $0-25 \%$ \\
\hline Barbosa [26] & 140 & $95.3 \%$ & $84.6 \%$ & $87 \%$ & $94 \%$ & $90.2 \%$ & $20-92.9 \%$ \\
\hline Zhang [27] & 319 & $86.7 \%$ & $91.4 \%$ & $75.6 \%$ & $95.3 \%$ & $96 \%$ & $0-90.5 \%$ \\
\hline Maia [28] & 242 & $80 \%$ & $84 \%$ & $71 \%$ & $90 \%$ & $66.7 \%$ & $8.7 \%-77 \%$ \\
\hline Rocha [29] & 143 & $80.4 \%$ & $94 \%$ & $52.4 \%$ & $95 \%$ & I & $0-72 \%$ \\
\hline Chaigeau [30] & 602 & $95 \% \%$ & I & $77.6 \%$ & $55 \%$ & I & $20-100 \%$ \\
\hline Rahal [32] & 1000 & / & / & / & / & / & $16-92 \%$ \\
\hline Grani [33] & 502 & $83.3 \%$ & $56.2 \%$ & $12.8 \%$ & $97.8 \%$ & / & $2-20 \%$ \\
\hline $\mathrm{Wu}$ [39] & 346 & $96 \%$ & $53 \%$ & $76 \%$ & $89 \%$ & $79 \%$ & \\
\hline
\end{tabular}

Barbosa et al. analyzed the correlation of ACR-TIRADS and ATA guidelines in the evaluation of 140 indeterminate thyroid lesions [26]. According to their study, the combination of US classification, ACR-TIRADS, and ATA along with TBSRTC is useful for detecting benign lesions in Bethesda III nodules and malignant lesions in Bethesda IV/V nodules. The ROM increased according to US suspicion categories $(p<0.001)$ for both US classifications (i.e., 
TIRADS and ATA). Whilst thyroid nodules with the lowest TIRADS categories had 95.3\% sensitivity and 94\% negative predictive value (NPV), the highest TIRADS categories were significantly associated with cancer.

Several other studies have also evaluated the use of US patterns to stratify the risk of malignancy for indeterminate thyroid lesions. Grani et al. studied 49 indeterminate lesions combined with TIRADS and ATA systems. They concluded that nodules classified as TIRADS 3 or as having a very low suspicion could be followed-up with FNA, whilst TIRADS $4 \mathrm{c}$ nodules had a high positive predictive value (PPV) of $71 \%$ with a suggestion for surgical procedure [33]. Moreover, Maia et al. studied 136 indeterminate thyroid lesions combining TIRADS with TBSRTC [28]. They found that Bethesda III nodules with a TIRADS 3 and 4 a had high sensitivity (80\%) and NPV (90\%), implying that conservative management was adequate. On the other hand, thyroid nodules scored as TIRAD 4c and 5 with Bethesda IV and V had a high ROM at 75\% and 76.9\%, respectively. Rocha et al. investigated 143 indeterminate thyroid lesions, classified as Bethesda III and IV, who were referred to surgery and they hey found a ROM ranging from $0 \%$ to $72 \%$ [29]. Chaigneau et al. studied 602 indeterminate thyroid nodules classified as TIRADS score $3,4 \mathrm{a}, 4 \mathrm{~b}$, and 5 with different ROM as $20.5 \%, 29 \%, 63.4 \%$, and $100 \%$, respectively [30].

Friedrich-Rust et al. demonstrated promising results in a study including three observers for 114 thyroid nodules [34]. They found that the interobserver agreement was only fair for TIRADS categories 2-5 (Cohen kappa-ck $=0.27, p=0.000001$ ) and TIRADS categories $2 / 3$ versus $4 / 5$ ( $c k=0.25, p=0.0020)$. The NPV was $92-100 \%$ for TIRADS categories 4 and 5 in the same study. Valderrabano et al. [31] and Barbosa et al. [26] concluded that there were no differences in the prevalence of malignancy between indeterminate nodules with low or intermediate ATA suspicious patterns, confirming that hypoechogenicity alone did not seem to improve the risk stratification of indeterminate lesions. In contrast, any additional suspicious US feature significantly increases the risk of malignancy of the indeterminate nodules. Rahal et al. assessed a significant association between TIRADS outcome and TBSRTC $(p<0.001)$ in the evaluation of 1000 retrospective thyroid nodules [32]. Benign Bethesda results (95.5\%) had been classified as TIRADS 2 or 3, whilst among those classified as TIRADS $4 \mathrm{c}$ and 5, the majority belonged to Bethesda VI $(68.2 \%$ and $91.3 \%$, respectively). Furthermore, among TIRADS $4 \mathrm{a}-\mathrm{c}$ and 5, the proportion of malignancy was $16 \%, 43.2 \%, 72.7 \%$, and $91.3 \%$, respectively. Hence, this study supports the role of TIRADS for the correct assessment and management of thyroid nodules [32]. Zhang et al. studied 319 thyroid nodules combining TIRADS classification and the contrast-enhanced ultrasound (CEUS) enhancement pattern of thyroid nodules concluding that the accuracy in the diagnosis was $96 \%$ especially for TIRADS class- 4 thyroid nodules [27].

Grani et al. assessed the performance of five internationally endorsed sonographic classification systems [33]. They included 502 cases classified with both the Italian classification system and TBSRTC. The application of the FNA criteria systems reduced the number of biopsies performed by $17.1 \%$ to $53.4 \%$ for the Italian and TBSRTC, respectively. Among the sonographic risk stratification systems, ACR-TIRADS allowed the largest reduction of biopsies (more than 50\%) and the lowest false negative rate (2.2\%). Middleton et al., in a multi-institutional reevaluation of thyroid nodules, found that TIRADS was favorably comparable with the ATA and the Korean society of thyroid radiology classifications in reducing the number of biopsies [35].

Other controversial areas for TIRADS include microcarcinoma, growth of nodules, number of nodules to be aspirated and the evaluation of cervical nodes [6]. A paper by Tessler et al. also discussed these issues [6]. Concerning the performance of FNAs for subcentimeter nodules, the ACR-TIRADS agree with other guidelines in limiting FNA of nodules smaller than $1 \mathrm{~cm}$, even if they are highly suspicious. Nevertheless, due to the possibility of active surveillance, ablation, or lobectomy for microcarcinoma, an FNA may be performed.

The committee defined the number of nodules to be biopsied [6]. They recommended one targets no more than two nodules defined by the most worrisome TIRADS. Among the 
criteria, size should be one of the primary criteria for FNA. Furthermore, the evaluation of cervical lymph nodes is a vital part of every thyroid sonographic examination, and it should be recommended for suspicious nodes.

Another point of discussion is represented by the growth of nodules [6]. The ACRTIRADS defines a significant enlargement when there is a $20 \%$ increase in at least two nodular dimensions and a minimal increase of $2 \mathrm{~mm}$, or a $50 \%$ or greater increase in volume, compared with the immediately previous US evaluation [6].

Yang et al. discussed the role of ARC-TIRADS in triaging thyroid follicular cells with papillary-like nuclear features obtained by FNA in order to evaluate the extent of surgery [37]. They found that ACR TI-RADS can be combined with morphology, including NIFTP among cytological diagnoses.

In another paper, Yang et al. studied 179 cases including $72(40.2 \%)$ noninvasive follicular thyroid neoplasm with papillary-like nuclear features (NIFTP), 37 (20.7\%) encapsulated FVPTC with invasion (EFVPTC), and 70 (39.1\%) infiltrative FVPTC (IFVPTC) without a capsule [38]. They underlined that either NIFTPs or minimally invasive EFVPTC have a circumscribed oval/round border and a hypoechoic rim, and hypervascularity with Doppler. On the other hand, the ultrasound findings for IFVPTCs found at least one of the malignant gray-scale features: markedly hypoechoic, taller-than-wide, microcalcifications, or blurred margins.

$\mathrm{Wu}$ studied the same correlation with TIRAD, including 346 thyroid FNAC. They found an overall 0.465 r-value between TI-RADS scores and TBSRTC categories. Furthermore, the comparative analysis between TBSRTC and TIRADS showed that sensitivity, specificity, PPV, NPV, and accuracy are $96 \%, 53 \%, 76 \%, 89 \%, 79 \%$ for TI-RADS vs. $100 \%$, 93\%, 96\%, 100\%, 97\% for TBSRTC, respectively $(p=0.038)$ [39].

\section{Other Thyroid Nodule Ultrasound Scoring Systems}

Lee et al. assessed the accuracy of rendering a US diagnosis for benign and malignant solid thyroid nodules using a different classification system comprised of five categories [36] (Table 2). These categories included: malignant, suspicious for malignancy, borderline, probably benign, and benign. The criteria, used for fitting the nodules into the different categories, focused on their hypoechogenicity, nodular margins, microcalcifications, a "taller-than-wider" shape, and associated regional lymphadenopathy. In their series of 103 thyroid lesions, Lee et al. demonstrated that this novel thyroid US system had $86 \%$ sensitivity, $95 \%$ specificity, $91 \%$ positive, and $92 \%$ negative predictive values, as well as $92 \%$ diagnostic accuracy in discriminating benign from malignant lesions [36]. Nonetheless, the suspicious for malignancy US category had a low diagnostic accuracy value, whilst all malignant US nodules were confirmed to be correctly categorized.

The British Thyroid Association (BTA) in 2014 provided guidelines for US scoring of thyroid nodules (BTA-U score) to assist in the management of thyroid cancer [40]. Briefly, it allows for stratifying thyroid nodules as benign, suspicious, or malignant based on ultrasound appearances termed U1-U5. They include five categories as U1 (normal parenchyma; U2 (benign); U3 (indeterminate); U4 (suspicious); and U5 (malignant). The categories are linked with different management. In fact, U2 nodules do not require FNA or follow-up imaging in the absence of concerning clinical features. The assignation of U3-U5 to nodules require FNA with further management based on resultant cytology, radiology and clinical findings. The US features should be combined with the cytological evaluation and the diagnostic categories. The Royal College of Pathologists in 2009 recommended the subdivision of the Thy-3 (indeterminate) category into Thy-3a (atypia) and Thy-3f (follicular neoplasm) [41,42].

Weller et al. studied 73 consecutive cases evaluated by five sonographers [40]. Their results suggested that there was substantial inter-observer agreement, culminating in 100\% sensitivity and negative predictive value, with low specificity (32\%) and specificity (34\%). On the other hand, a study by Brophy et al. using the BTA system on 151 indeterminate 
thyroid lesions (Thy3) found no statistically significant differences in the ROM between Thy3a and Thy3f [42].

Ulisse et al. combined the Italian system for classifying thyroid nodules with the TIRADS scoring system in a series of 70 thyroid lesions classified as indeterminate lesions (TIR3A or TIR3B) [43]. The authors reported a different rate of malignancy between TIR3A $(13 \%)$ and TIR3B (44.5\%). They also subclassified their patients into three subgroups showing low $(8.3 \%)$, indeterminate $(21.4 \%)$, and high $(80 \%)$ risk of malignancy. Adoption of the second edition of the Italian cytologic classification system has offered better stratification of malignant risk for indeterminate thyroid lesions [11]. This finding was corroborated by Chng et al. using the BTA system and TIRADS, confirming that the risk of malignancy increased from TIRADS 4A (14.3\%), TIRADS 4B (23.1\%), TIRADS 4C $(87.5 \%)$, and TIRADS $5(100 \%)$ [44].

The KSThR published their first recommendation in 2011 for utilizing an US-based diagnosis to assist with the management of thyroid nodules [14]. Subsequently in 2016, a taskforce revised these Korean recommendations [8]. Of note, their changes included revising the US malignancy risk stratification system for thyroid nodules now known as the Korean Thyroid Imaging Reporting and Data System (K-TIRADS), adding a risk stratification system of cervical lymph nodes on the basis of US and computed tomography (CT) features, and recommendations for image-guided ablation of benign thyroid nodules. Their data included a detailed analysis of thyroid nodules encompassing: (1) internal composition (solid, predominantly solid, cystic, predominantly cystic); (2) echogenicity (marked hypoechogenicity, mild hypoechogenicity, isoechogenicity, hyperechogenicity); (3) shape (round to oval, irregular); (4) orientation (parallel, non-parallel); (5) margin (smooth, spiculated, ill-defined); (6) calcification (microcalcification, macrocalcification, rim calcification); (7) halo (present or absent); (8) spongiform (present or not); (9) colloid (present or not); and (10) vascularity (from type 1 to 4 ). Using this score, the system defines five categories including no nodule, benign category with a $<3 \%$ ROM, low suspicious category with a $3-15 \%$ ROM, intermediate suspicion with a $15-50 \%$ ROM, and high suspicion category with $>60 \%$ ROM [45].

\section{Conclusions}

The adoption of an ultrasound (US) system for classifying thyroid nodules is useful for tailoring the diagnostic approach when evaluating these lesions and combining their workup with FNA biopsy [45-48]. Accurate categorization of thyroid nodules based on an US classification system, irrespective of whether it is the ACR-TIRADS or an alternative system, may help physicians in predicting their ROM and thus rationalize adequate management. Furthermore, combined analysis including TIRADS in concert with the patient's age, gender, clinical findings, and thyroid nodule size is essential in determining the preFNA ROM. Even if TIRADS or another related US-based system demonstrates satisfactory sensitivity in detecting malignant thyroid nodules, it is unlikely going to replace FNA, as the latter remains the gold standard to define the nature of these nodules, especially when cytomorphology is combined with ancillary molecular testing for indeterminate lesions. However, when TIRADS is combined with US-guided FNA this has been shown to greatly improve the accuracy of diagnosing malignant thyroid nodules.

Author Contributions: Conceptualization: E.D.R., L.P.; methodology: E.D.R., L.P., G.F., M.R.; software: L.P.; validation: E.D.R., L.P., G.F., M.R.; formal analysis: E.D.R., L.P.; investigation: E.D.R., L.P.; resources: E.D.R., L.P.; data curation: E.D.R., L.P., G.F., M.R.; writing—original draft preparation: E.D.R., L.P.; writing—review and editing: E.D.R., L.P., G.F., M.R. visualization: E.D.R., L.P.; supervision: E.D.R.; project administration: E.D.R., L.P.; funding acquisition: E.D.R., G.F. All authors have read and agreed to the published version of the manuscript."

Funding: This research did not receive any specific grant from any funding agency in the public, commercial or not-profit sectors.

Conflicts of Interest: The authors have no conflict of interests. 


\section{References}

1. Al Dawish, M.A.; Rober, A.A.; Thabet, M.A.; Braham, R. Thyroid nodule management: Thyroid-stimulating hormone, ultrasound and cytological classification system for predicting malignancy. Cancer Inform. 2018, 17, 1-9. [CrossRef]

2. Grani, G.; Sponziello, M.; Pecce, V.; Ramundo, V.; Durante, C. Contemporary thyroid evaluation and management. J. Clin. Endocrinol. Metab. 2020, 105, 2869-2883. [CrossRef]

3. Ardakani, A.A.; Mohammadzadeh, A.; Yaghoubi, N.; Ghaemmaghami, Z.; Reiazi, R.; Jafari, A.H.; Hekmat, S.; Shiran, M.B.; Bitarafa-Rajabi, A. Predictive quantitative sonographic features on classification of hot and cold thyroid nodules. Eur. J. Radiol. 2018, 101, 170-177. [CrossRef] [PubMed]

4. Tappouni, R.R.; Itri, J.N.; Mc Queen, T.S.; Lalwani, N.; Ou, J.J. ACR TI-RADS: Pitfalls, solutions and future directions. Radiographics 2019, 39, 2040-2052. [CrossRef] [PubMed]

5. Grant, E.G.; Tessler, F.N.; Hoang, J.K.; Langer, J.E.; Beland, M.D.; Berland, L.L.; Cronan, J.J.; Desser, T.S.; Frates, M.C.; Hamper, U.M.; et al. Thyroid ultrasound reporting lexicon: White paper of the ACR thyroid imaging reporting and data system (TIRADS) committee. J. Am. Coll. Radiol. 2015, 12, 1272-1279. [CrossRef] [PubMed]

6. Tessler, F.N.; Middleton, W.D.; Grant, E.G.; Hoang, J.K.; Berland, L.L.; Teefey, S.A.; Cronan, J.J.; Beland, M.D.; Desser, T.S.; Frates, M.C.; et al. ACR Thyroid Imaging, Reporting and Data System (TI-RADS): White Paper of the ACR TI-RADS Committee. J. Am. Coll. Radiol. 2019, 14, 587-595. [CrossRef] [PubMed]

7. Hauger, B.R.; Alexander, E.K.; Bible, K.C.; Doherty, G.M.; Mandel, S.J.; Nikiforov, Y.E.; Pacini, F.; Randolph, G.W.; Sawka, A.M.; Schlumberger, M.; et al. 2015 American thyroid association management guidelines for adult patients with thyroid nodules and differentiated thyroid cancer: The American thyroid association guidelines task force on thyroid nodules and differentiated thyroid cancer. Thyroid 2016, 26, 1-33.

8. Shin, J.H.; Back, J.H.; Chung, J.; Ha, E.J.; Kiim, J.H.; Lee, Y.H.; Lim, H.K.; Moon, W.J.; Na, D.G.; Park, J.S.; et al. Ultrasonography diagnosis and imaging-based management of thyroid nodules: Revised Korean society of thyroid radiology consensus statement and recommendations. Korean J. Radiol. 2016, 17, 370-395. [CrossRef]

9. Ali, S.; Cibas, E.S. The Bethesda System for Reporting Thyroid Cytopathology, 2nd ed.; Springer: Berlin, Germany, 2018.

10. Nardi, F.; Basolo, F.; Crescenzi, A.; Fadda, G.; Frasoldati, A.; Orlandi, F.; Palombini, L.; Papini, E.; Zini, M.; Pontecorvi, A.; et al. Italian consensus for the classification and reporting of thyroid cytology. J. Endocrinol. Investig. 2014, 37, 593-599. [CrossRef]

11. Fadda, G.; Basolo, F.; Bondi, A.; Bussolati, G.; Crescenzi, A.; Nappi, O.; Nardi, F.; Papotti, M.; Taddei, G.; Palombini, L.; et al. Cytological classification of thyroid nodules. Proposal of the SIAPEC-IAP italian consensus working group. Pathologica 2010, 102, 405-406.

12. Horvarth, E.; Majlis, S.; Rossi, R.; Franco, C.; Niedmann, J.P.; Castro, A.; Dominguez, M.S.L. An ultrasonogram reporting system for thyroid nodules stratifying cancer risk for clinical management. J. Clin. Endocrinol. Metab. 2009, 94, 1748-1751. [CrossRef]

13. Park, J.Y.; Lee, H.J.; Jang, H.W.; Kim, H.K.; Yi, J.H.; Lee, W.; Kim, S.H. A proposal for a thyroid imaging reporting and data system for ultrasound features of thyroid carcinoma. Thyroid 2009, 19, 1257-1264. [CrossRef] [PubMed]

14. Kwak, J.Y.; Han, K.H.; Yoon, J.H.; Moon, H.J.; Son, E.J.; Park, S.H.; Jung, H.K.; Choi, J.S.; Kim, B.M.; Kim, E.K. Thyroid imaging reporting and data system for US features of nodules: A step in establishing better stratification of cancer risk. Radiology 2011, 260, 892-899. [CrossRef]

15. Na, D.G.; Back, J.H.; Sung, J.Y.; Kim, J.H.; Kim, J.K.; Choi, Y.J.; Seo, H. Thyroid imaging reporting and data system risk stratification of thyroid noduels: Categorization based on solidity and echogenicity. Thyroid 2016, 26, 562-572. [CrossRef]

16. Russ, G.; Bonnema, S.J.; Erdogan, M.F.; Durant, C.; Ngu, R.; Leenhardt, L. European thyroid association guidelines for ultrasound malignancy risk stratification of thyroid nodules in adults: The EU-TIRADS. Eur. Thyroid. J. 2017, 6, 225-237. [CrossRef]

17. Frates, M.C.; Benson, C.B.; Charboneau, J.W.; Cibas, E.S.; Clark, O.H.; Coleman, B.G.; Cronan, J.J.; Doubilet, P.M.; Evans, D.B.; Goellner, J.R.; et al. Management of thyroid nodules detected at US: Society of radiologists in ultrasound consensus conference statement. Radiology 2005, 237, 794-800. [CrossRef]

18. Gharib, H.; Papini, E.; Garber, J.R.; Duick, D.S.; Harrell, R.M.; Hegedüs, L.; Paschke, R.; Valcavi, R.; Vitti, P. AACE/ACE/AME Task Force on Thyroid Nodules American association of clinical endocrinologist, american college of endocrinology, and associazione medici endocrinologi medical guidelines for clinical practice for the diagnosis and management of thyroid nodules: 2016 update. Endocrin. Pract. 2016, 22, 622-639.

19. National comprehensive Cancer Network. NCCN Clinical Practice Guidelines in Oncology and (NCCN Guidelines) and Thyroid Carcinoma (Version 2.2014); National Comprehensive Cancer Network: Washington, DC, USA, 2014.

20. Atilla, F.D.; Saydam, B.O.; Erarslan, N.A.; Unlu, A.G.; Yasar, H.Y.; Ozer, M.; Akinci, B. Does the ACR TIRADS scoring allow us to safely avoid nnecessary thyroid biopsy? single center analysis in a large cohort. Endocrine 2018, 61, 398-402. [CrossRef]

21. Ha, E.J.; Na, D.G.; Back, J.H.; Sung, J.Y.; Kim, J.H.; Kang, S.Y. US fine needle aspiration biopsy for thyroid malignancy: Diagnostic performance of seven society guidelines applied to 2000thyroid nodules. Radiology 2018, 287, 893-900. [CrossRef]

22. Eze, O.P.; Cai, G.; Baloch, Z.W.; Khan, A.; Virk, R.; Hammers, L.W.; Udelsman, R.; Roman, S.A.; Sosa, J.A.; Carling, T.; et al. Vanishing thyroid tumors. A diagnostic dilemma after ultrasonography-guided fine needle aspiration. Thyroid 2013, 23, 194-200. [CrossRef] [PubMed]

23. Bhatia, P.; Deniwar, A.; Mohamed, H.E.; Sholl, A.; Murad, F.; Aslam, R.; Kandil, E.; Bhatia, P. Vanishing tumors of thyroid: Histological variations after fine needle aspiration. Gland Surg. 2016, 5, 270-277. [CrossRef] [PubMed] 
24. Kholová, I. Vanishing thyroid gland tumors: Infarction as consequence of FNA? Diagn. Cytopathol. 2016, 44, 568-573. [CrossRef] [PubMed]

25. Shayganfar, A.; Hashemi, P.; Esfahani, M.M.; Ghanei, A.M.; Moghadam, N.A.; Ebrahimian, S. Prediction of thryoid nodule maliganncy using thyroid imaging reporting and data system (TI-RADS) and nodule size. Clin. Imag. 2020, 60, 232-237. [CrossRef] [PubMed]

26. Barbosa, T.L.M.; Junior, C.O.M.; Graf, H.; Cavalvanti, T.; Trippia, M.A.; da Silveira Ugino, R.T.; de Oliveira, G.L.; Granella, V.H.; de Carvalho, G.A. ACR TI-RADS and ATA US scores are helful for the management of thyroid nodules with indeterminate cytology. BMC Endocr. Disord. 2019, 19, 112. [CrossRef] [PubMed]

27. Zhang, Y.; Zhou, P.; Tian, S.M. Usefulness of combined use of contrast-enhanced ultrasound and TI-RADS classification for the differentiation of benign from malignant lesions of thyroid nodules. Eur. Radiol. 2017, 27, 1527-1536. [CrossRef]

28. Maia, F.F.R.; Matos, P.S.; Pavin, E.J.; Vassallo, J.; Zantut-Wittmann, D.E. Thyroid imaging reporting and data system score combined with Bethesda system for maliganncy risk stratification in thyroid nodules with indeterminate results on cytology. Clin. Endocrinol. 2015, 82, 439-444. [CrossRef] [PubMed]

29. Rocha, T.G.; Rosario, P.W.; Silva, A.L.; Nunes, M.B.; Calsolari, M.R. Ultrasonography classification of the american thyroid association for predicting malignancy in thyroid nodules $>1 \mathrm{~cm}$ with indterminate cytology: A proscpective study authors. Horm. Metab. Res. 2018, 50, 597-601.

30. Chaigeau, R.; Russ, G.; Royer, B.; Bigorgne, C.; Bienvenu-Perrard, M.; Rouxel, A.; Leenhardt, L.; Belin, L.; Buffet, C. TI-RADS score is of limited clinical value for risk stratification of indeterminate cytological resluts. Eur. J. Endocrinol. 2018, 179, 13-20. [CrossRef] [PubMed]

31. Valderrabano, P.; Mcgettigan, M.J.; Iam, C.A. Thyroid nodules with indeterminate cytology: Utility of the american thyroid association sonographic patterns for cancer risk. Thyroid 2018, 28, 1-29. [CrossRef]

32. Rahal, A.J.; Falsarella, P.M.; Rocha, R.D.; Lima, J.P.; Iani, M.J.; Vieira, F.A.; Queiroz, M.R.; Hidal, J.T.; Francisco Neto , M.J.; Garcia, R.G.; et al. Correlation of thyroid imaging reporting and data system (TI-RADS) and fine needle aspiration: Experience in 1000 nodules. Einstein 2016, 14, 119-123. [CrossRef] [PubMed]

33. Grani, G.; Lamartina, L.; Ascoli, V.; Bosco, D.; Biffoni, M.; Giacomelli, L.; Maranghi, M.; Falcone, R.; Ramundo, V.; Cantisani, V.; et al. Reducing the number of unnecessary thyroid biopsies while improving diagnostic accuracy: Toward the right TIRADS. J. Clin. Endocrinol. Metab. 2019, 104, 95-102. [CrossRef]

34. Friedrich-Rust, M.; Meyer, G.; Dauth, N.; Berner, C.; Bogdanou, D.; Herrmann, E.; Zeuzem, S.; Bojunga, J. Interobserver agreement of thyroid imaging reporting and data system (TI-RADS) and strain elastography for the assessment of thyroid nodules. PLoS ONE 2013, 8, e77927. [CrossRef]

35. Middleton, W.D.; Teefey, S.A.; Reading, C.C.; Langer, J.E.; Beland, M.D.; Szabunio, M.M.; Desser, T.S. Comparison of performance characteristics of American college of radiology TI-RADS, Korean society of thyroid radiology TIRADS, and American thyroid association guidelines. Am. J. Roentgenol. 2018, 210, 1148-1154. [CrossRef] [PubMed]

36. Lee, Y.H.; Kim, D.W.; In, H.S.; Park, J.S.; Kim, S.H.; Eom, J.W.; Kim, B.; Lee, E.J.; Rho, M.H. Differentation between benign and malignant solid thyroid nodules using an US classification system. Korean J. Radiol. 2011, 12, 559-567. [CrossRef] [PubMed]

37. Yang, G.C.H.; Fried, K.O.; Scognamiglio, T. Can cytology and the Thyroid Imaging, Reporting, and Data System (TI-RADS) identify noninvasive follicular thyroid neoplasm with papillary-like nuclear features (NIFTP) before surgery. J. Am. Soc. Cytopathol. 2020, 9, 159-165. [CrossRef] [PubMed]

38. Yang, G.C.; Fried, K.O.; Scognamiglio, T. Sonographic and cytologic differences of NIFTP from infiltrative or invasive encapsulated follicular variant of papillary thyroid carcinoma. A Review of 179 Cases. Diagn. Cytopath. 2017, 45, 533-541. [CrossRef] [PubMed]

39. $\mathrm{Wu}, \mathrm{M}$. A correlation study between thyroid imaging report and data systems and the Bethesda system for reporting thyroid cytology with surgical follow-up-An ultrasound-trained cytopathologist's experience. Diagn. Cytopathol. 2020. [CrossRef]

40. Weller, A.; Sharif, B.; Qarib, M.H.; St Leger, D.; De Silva, H.S.; Lingam, R.K. British thyroid association 2014 classification ultrasound scoring of thyroid nodules in predicting maliganncy: Diagnostic performance and inter-observer agreement. Ultrasound 2020, 28, 4-13. [CrossRef]

41. Cross, P.; Chandra, A.; Giles, T.; Johnson, S.; Kocjan, G.; Poller, D.; Stephenson, T. Guidance on the Reporting of Thyroid Cytologyspecimens; Royal College of Pathologists: London, UK, 2009. Available online: http:/ / wwwrcpathorg/Resources/RCPath/ (accessed on 1 January 2016).

42. Brophy, C.; Mehanna, R.; McCarthy, J.; Tuthill, A.; Murphy, M.S.; Sheahan, P. Outcome of subclassification of indeterminate (Thy 3) thyroid cytology into Thy 3a and Thy 3f. Eur. Thyroid. J. 2015, 4, 246-251. [CrossRef]

43. Maia, F.F.; Matos, P.S.; Pavin, E.J.; Zantut-Wittmann, D.E. Thyroid imaging reporting and data system score combined with the new italian classification for thyroid cytology improves the clinical management of indeterminate nodles. Int. J. Endocrinol. 2017. [CrossRef]

44. Chng, C.L.; Kurzawinski, T.R.; Beale, T. Value of sonographic features in predicting malignancy in thyroid nodules diagnosed as follicular neoplasm on cytology. Clin. Endocrinol. 2015, 83, 711-716. [CrossRef]

45. Moon, W.J.; Baek, J.H.; Jung, S.L.; Kim, D.W.; Kim, E.K.; Kim, J.Y.; Kwak, J.Y.; Lee, J.H.; Lee, J.H.; Lee, Y.H.; et al. Ultrasonography and the ultrasound-based management of thyroid nodules: Consensus statement and recommendations. Korean J. Radiol. 2011, 12, 1-14. [CrossRef] [PubMed] 
46. Rosario, P.W.; da Silva, A.L.; Nunes, M.B.; Borges, M.A.R. Risk of Malignancy in Thyroid Nodules Using the American College of Radiology Thyroid Imaging Reporting and Data System in the NIFTP Era. Horm. Metab. Res. 2018, 50, 735-737. [CrossRef] [PubMed]

47. Singaporewalla, R.M.; Hwee, J.; Lang, T.U.; Desai, V. Clinico-pathological Correlation of Thyroid Nodule Ultrasound and Cytology Using the TIRADS and Bethesda Classifications. World J. Surg. 2017, 41, 1807-1811. [CrossRef] [PubMed]

48. Tan, H.; Li, Z.; Li, N.; Qian, J.; Fan, F.; Zhong, H.; Feng, J.; Xu, H.; Li, Z. Thyroid imaging reporting and data system combined with Bethesda classification in qualitative thyroid nodule diagnosis. Medicine 2019, 98, 50. [CrossRef] [PubMed] 